RESEARCH ARTICLE

\title{
The legitimizing role of accent on discrimination against immigrants
}

\author{
Luana Elayne Cunha de Souza*, Cicero Roberto Pereirat, $\neq$, Leoncio Camino $\neq$, \\ Tiago Jessé Souza de Limał \& Ana Raquel Rosas Torresł \\ * University of Fortaleza, Fortaleza, Brazil \\ $\dagger$ Institute of Social Sciences of the University of Lisbon, Lisbon, Portugal \\ ‡ Federal University of Paraíba, João Pessoa, Brazil
}

\author{
Correspondence \\ Luana Souza, Postgraduate Program in \\ Psychology, University of Fortaleza, Brazil. \\ Postal Code: 60811-905. \\ E-mail luana_elayne@hotmail.com
}

Received: 23 March 2015

Accepted: 14 April 2016

http://dx.doi.org/10.1002/ejsp.2216

Keywords: accent, prejudice, discrimination, legitimization

\begin{abstract}
This article analyses the influence of accent on discrimination against immigrants by examining the hypothesis that accent leads to discrimination only in more prejudiced individuals, merely because people speaking with a native accent are perceived to be better qualified than those whose accent is nonstandard. In Study $1(N=71)$, we found that only prejudiced individuals use accent to discriminate against immigrants. In Study $2(N=124)$, we replicated this effect and found that the influence of accent on discrimination is mediated by the perceived quality of the accent. Study $3(N=105)$ replicated the previous results even after controlling for the effect of stereotyping. These results are the first experimental illustration of the hypothesis that accent triggers intergroup discrimination only among prejudiced individuals because they evaluate native accents as being qualitatively better than accents of immigrants, thereby legitimizing ingroup bias.
\end{abstract}

Non-standard accents are one of the most salient characteristics of individuals from other countries who come to live, work, or study in a host country. An accent identifies and potentially stigmatizes people as not being native born (Derwing \& Munro, 2009; Moyer, 2004) or not being native speakers (Kinzler, Dupoux, \& Spelke, 2007). In fact, more than 40 years of research in this field has established that a speaker's accent constitutes an important part of his/her social identity and conveys a considerable amount of information that is useful in evaluating a target (Edwards, 1999; Giles \& Johnson, 1987; Gluszek \& Dovidio, 2010; Lippi-Green, 1997). This occurs because accent plays a central role in the way individuals categorize speakers into social groups, especially in relation to ethnic categorization (Rakić, Steffens, \& Mummendey, 2011). Indeed, previous research suggests that non-standard accents are associated with negative evaluations of the speaker (e.g., Fuertes, Gottdiener, Martin, Gilbert, \& Giles, 2012; Grondelaers, van Hout, \& Steegs, 2010; Hosoda, Stone-Romero, \& Walter, 2007; Ko, Judd, \& Blair, 2006; Lev-Ari \& Keysar, 2010; Lindemann, 2003, 2005), because the accent elicits native individuals' negative attitudes towards the social category to which the non-standard speaker belongs (Boyd, 2003; Bresnahan, Ohashi, Nebashi, Liu, \& Shearman, 2002; Fuertes et al., 2012; Lindemann, 2003). However, as far as we know, no research has yet been published demonstrating the influence of accent on actual discrimination against non-standard speakers, nor has there been any elucidation of the social and psychological process underlying the accent effect.
Specifically, we do not know yet whether accent is sufficient to lead to discrimination against non-standard speakers or whether this discrimination is caused by a combination of accent and a negative evaluation associated with the social categories that the accent reveals. In this paper we shed light on this question by proposing that a target's accent leads to discrimination against a person only when listeners already have a prejudiced attitude against the social groups to which the target belongs. This possibility suggests that the mere salience of accent does not necessarily imply ingroup bias. Indeed, Park and Judd (2005) reviewed the relationship between categorization and ingroup bias and argued that although categorization under some circumstances may lead to bias, an increase in the strength of category boundaries is not necessarily associated with an increase in ingroup bias (refer also to Costa-Lopes, Pereira, \& Judd, 2014). Although the question remains unresolved, we believe that consideration of the role played by prejudice on the influence of accent on discrimination could help to resolve this issue. Specifically, we propose the hypothesis that accent can be innocuous in motivating discriminatory behaviour in non-prejudiced individuals but can have a pervasive influence on the behaviour of highly prejudiced persons.

Nevertheless, because discrimination is discouraged by the anti-prejudice norm (Dovidio \& Gaertner, 2000), even more prejudiced individuals need to engage in a legitimizing process in order to discriminate and they do so by using a seemingly unprejudiced justification (e.g., Gaertner \& Dovidio, 2005). Indeed, research 
on the legitimation of social inequality (refer to Costa-Lopes, Dovidio, Pereira, \& Jost, 2013 for a review) suggests that individuals need to legitimize their discriminatory behaviour because this resolves the psychological conflict between two contrasting motives: one that promotes prejudiced attitudes and another that promotes behaviours guided by egalitarian and fair justice motives (e.g., Lima-Nunes, Pereira, \& Correia, 2013). This possibility highlights the specific role played by different aspects of accent in discrimination against minority groups, which is an under-explored avenue of research. What we propose is that more prejudiced individuals discriminate against a target with a nonstandard accent because they use information about accents as a legitimizing mechanism for discriminating against non-standard speakers.

\section{The Legitimizing Role of Accent on Discrimination}

Prejudiced individuals can use information provided by accents in many different ways to legitimize discriminating against non-standard speakers. For instance, because accent reveals target group membership, stereotypes associated with the speaker's group can justify ingroup bias (Allport, 1954; Tajfel, 1984; Yzerbyt, Rocher, \& Schadron, 1997). As stated by Operario and Fiske (2001), stereotypes are consequences of the more general process of categorization. The Stereotype Content Model (Fiske, Cuddy, Glick, \& Xu, 2002) argues that stereotypes are captured by two universal dimensions (warmth and competence) and that these dimensions are predicted by two variables long identified as important in intergroup relations-status and competition. Warmth is the perception that members of the group are tolerant, warm, good natured, and sincere, while competence is the perception that members of the group are competent, confident, independent, competitive, and intelligent. The greater attribution of warmth and the lesser attribution of competence stereotypes to characterize immigrants can be used by individuals when making decisions in critical social situations (Fiske et al., 2002; Lee $\&$ Fiske, 2006). In fact, warmth-competence stereotype content shows up in situations involving language skills (e.g., Yzerbyt, Provost, \& Corneille, 2005): people with non-standard accents (e.g., Scottish accents in UK and Chicano accents in the USA) are perceived to be less competent but simultaneously friendly (Bradac, 1990; Ruscher, 2001). This information can be pivotal when a manager needs to make decisions about hiring applicants for a job.

In addition to the role played by accent in stereotyping, accent provides further information about people, legitimatizing discrimination against them. Individuals evaluate the extent to which the quality of an accent conforms to socially more desirable standards of speaking. Accordingly, the way a person speaks can be used as a basis for making arbitrary evaluations and, unlike many other forms of discrimination, is commonly accepted and perceived as legitimate by society (Gluszek
\& Dovidio, 2010). For instance, Ng (2007) argues that accent justifies discrimination because the perceived quality of a group's language provides a legal justification for preferential treatment over other linguistic groups, 'making it seemingly rational on the grounds that a particular language competence is necessary for becoming a bona fide citizen, for performing well in the job, or for benefiting from university education' (p. 108). In addition, Lippi-Green (1997) states that individuals feel no compunctions about language-based discrimination because they act as if accents were a litmus test for exclusion, an excuse to turn away, to refuse to recognize the other. In this sense, an individual's perception of the quality of a target's accent might function as a justifiable reason for discriminating against this target in a way that allows the individual to see his/her behaviour as correct and legitimate.

Examples of this kind of discrimination can be found in recent research into how speakers with non-standard accents are disadvantaged in the workplace (Hosoda $\delta$ Stone-Romero, 2010; Huang, Frideger, \& Pearce, 2013). In a survey of 26 out of 27 European Union countries, $34 \%$ of a representative sample of respondents believed that a job applicant's way of speaking (principally accent) would put him or her at a disadvantage compared with an equally qualified, non-accented candidate. Among managers in a position to hire, this figure rose to $45 \%$ (European Commission, 2008). These results can be explained by the fact that prejudiced attitudes affect behaviour and decisions in both conscious and unconscious ways (Devine, 1989; Dovidio, 2001), by allowing employers to decide whether having an accent constitutes a communicative impairment.

According to our rationale, prejudiced individuals are more sensitive to social categories made salient by the accent of a speaker. Subsequently, they are likely to perceive the quality of a non-standard accent to be lower than that of a standard one and will then consider it legitimate to hire a native speaker rather than an immigrant for a particular job. We argue, thus, that only more prejudiced individuals will discriminate against a speaker on the basis of his/her immigrant accent (vs. a native one) because they are more motivated to perceive the quality of an accent as a justifiable reason for not hiring a candidate who speaks with a non-standard accent.

In summary, in this paper we propose that individuals speaking with non-standard accents will trigger discrimination against themselves in highly prejudiced people. This means that prejudice moderates the influence of speakers' accent on discrimination against them; that is, the effect of accent is motivated by prejudice. Moreover, we argue that the assessment of accents works as a legitimizing mechanism for discrimination in that the assessment of non-standard accents as being worse than standard accents is perceived as a legitimate reason for discrimination against immigrants. Accordingly, this implies that assessment of accents should function as a mediator of the influence that the perception of immigrant 
versus native accents has in discrimination against immigrants. So if the psychological process occurs in this way, it means that a mediated moderation exists in the sense that accent discrimination occurs only in prejudiced individuals, but even prejudiced individuals need to legitimize discrimination, so the assessment of accent functions as a mediator of the process.

\section{Overview of Studies}

Through three studies, we examined how an immigrant versus native accent influences discrimination against immigrants and whether the perceived quality of an accent plays a legitimizing role in this discrimination in Portugal. These studies were conducted with a decision-making scenario used in recruiting candidates for a job. We chose Brazilian immigrants as our target group for two reasons. First, it is the largest immigrant community that is legally resident in Portugal. Second, although Brazilian immigrants speak the same language as native Portuguese nationals, Brazilian and European Portuguese accents are easily distinguishable by listeners.

First, we conducted a pilot study to test whether a candidate's accent is perceived as a legitimate reason for not hiring an immigrant who applied for a job. Then, in Study 1 we tested the hypothesis that accent influences discrimination against immigrants and that this influence is moderated by prejudice. In Study 2, we replicated and extended the previous study by testing the hypothesis that the influence of an accent in activating discrimination in more prejudiced individuals is mediated by the perceived quality of the accent. In Study 3, we replicated the mediated-moderation effect and went further, by demonstrating the influence of the targets' accents in discrimination even after taking into account stereotypes about the targets.

\section{Pilot Study}

The aim of this study was to test the hypothesis that using information about accents to decide in favour of an ingroup target by discriminating against an immigrant is perceived as more legitimate than a decision that does not take the target's accent into account. The subjects were 27 female and 10 male Portuguese university students $\left(M_{\text {age }}=20.4, S D=3.75\right)$, who were randomly allocated to one of two conditions (decision based on candidate's accent versus not based on candidate's accent). The participants read a text in which a director of human resources required help to choose between one of two candidates for a job. The only difference between the two candidates was that one of them spoke with a Brazilian accent. Thus, the director decided to choose the candidate speaking with a native accent. We defined a 'Brazilian accent' as the accent of a Brazilian man who lives and looks for a job in Portugal, not a Brazilian tourist. It is important to distinguish these two target groups. While Brazilian tourists typically are not familiar with the way of speaking Portuguese in Portugal, Brazilian immigrants already have some contact with the manner of speaking in Portugal and therefore try to use local colloquialisms. This characterize them as specific targets, different from tourists who do not represent a threat to the status of the ingroup. The goal here is to analyse what people think of this particular group (i.e., Brazilian immigrants) and not Brazilians in general. Specifically, the text used was as follows:

A reputed company invited candidates to apply for a series of jobs in business consulting and initiated a process of recruitment and selection. The company's director of human resources received five applications. After a detailed analysis of the candidates' CVs, the director selected the two best candidates for a telephone interview. During the interview, the director failed to notice any significant differences between the two candidates, except that one of them spoke with a Brazilian accent.

In both experimental conditions, we presented a justification for the director's behaviour, but in one of them we used the candidate's accent for justification and in the other condition we did not mention the accent. In the condition of deciding mentioning the candidate's accent, the participants read that 'the director decided to hire the candidate speaking with a European Portuguese accent because he thought that he/she best fit the role to be performed at the company, which is to interact with customers who consider the accent of the Portuguese spoken in Portugal more understandable and correct'. In the condition of deciding without mentioning the candidate's accent, the participants read that the director decided to hire the Portuguese candidate because after listening to the candidates he dispelled any questions that he might have about what would be the best choice. After reading the text, the participants answered a 7-point measure-of-legitimacy questionnaire evaluating whether the decision to select the Portuguese candidate was correct, appropriate, necessary, and legitimate. A mean score of these items was created $(\alpha=.92)$.

We hypothesized that if accent is perceived as a legitimate reason for discrimination, the participants should evaluate the decision to hire the Portuguese candidate as more legitimate, correct, appropriate, and necessary in the 'mentioning accent condition' than in the 'non-mentioning accent condition'. A $t$-test for independent samples showed that the participants judged as more legitimate the hiring decision in the mentioning accent condition $(M=4.30, S D=1.31)$ than in the non-mentioning accent condition $(M=3.25, S D=1.18), t(35)=-2.56$, $p=.015$. In addition, we compared the means obtained in each condition with the midpoint of the scale and found that in the control condition (non-mentioning accent condition), discrimination was clearly not legitimate because the mean was significantly below the midpoint, $t(16)=-2.62, p=.018$. In contrast, in the experimental condition it was above the midpoint, but this difference was not significant, $t(19)=1.02, p=.320$. 
Thus, the data gathered in this pilot study support our hypothesis that accent is perceived as a legitimate reason for favouring ingroup rather than outgroup speakers.

\section{Study 1}

The pilot study showed that information about the target's accent is perceived as a fair and legitimate reason to discriminate. This study aimed to go further, by testing the hypothesis that discrimination against nonnative speakers is influenced by the target's accent only in individuals who hold prejudiced attitudes against that social category activated by the speaker's accent. In this sense, we proposed that the target's accent (native vs. non-native) will influence discrimination in more-prejudiced individuals but not in lessprejudiced ones. The participants were invited to engage in an online study conducted using a decisionmaking scenario used in recruiting candidates for a job. We presented five CVs and then stated that only two candidates had been selected for interview. In the next section we said that the participants would listen to an excerpt from an interview with one of the candidates. We manipulated the candidates' accents, which were either European or Brazilian Portuguese. The participants then indicated the extent to which each applicant should be hired (discrimination measure). According to our rationale, only individuals highly prejudiced against Brazilian immigrants would use the target's accent in their decision about hiring; that is, the target speaking with a Brazilian immigrant accent will be hired less often than the target speaking with a Portuguese accent, indicating discrimination against the Brazilian immigrant based on his accent. Otherwise, for low-prejudiced individuals, there will be no difference in hiring the Portuguese or the Brazilian candidate, indicating absence of discrimination.

\section{Method}

Participants and Design. Seventy-one Portuguese university students participated in this study $\left(M_{\text {age }}=21.8, S D=4.27 ; 34\right.$ male and 37 female $)$. The participants were randomly allocated to one of two conditions (Portuguese accent vs. Brazilian accent) in a between-subject single-factor design; 35 participants evaluated the Brazilian candidate and 36 participants evaluated the Portuguese candidate.

Accent Manipulation. All participants heard a 23-second excerpt from a job interview in which the candidate introduced himself. Both conditions had the same text and duration, the only difference being the target's accent, which was recorded either by a native Portuguese man or a native Brazilian man. The excerpt spoken by the targets was as follows:
I am applying for the position of business consultant in the area of telecommunications and information technology. I have a degree in management. I have three years' experience in this area and recently completed a postgraduate degree in business administration. I am also available to work full time in the offices of Amoreiras, Saldanha, and Parque Expo.

Discrimination measure. We operationalized discrimination by asking the participants to 'consider the information that you have about the candidate. If you were the manager of the company, what is the likelihood of your hiring the candidate?' The participants chose answers from a 4-point scale varying from 1 (not at all likely) to 4 (very likely).

Prejudice Measure. We measured prejudice against Brazilian immigrants by using six items from the Portuguese version of the blatant and subtle prejudice scale (Lima-Nunes et al., 2013; Pettigrew \& Meertens, 1995; Vala, Lopes, \& Lima, 2008). We selected the best six items having as a criterion those with the highest factor loadings in the study by Lima-Nunes et al. (2013) of prejudice and discrimination against Brazilian immigrants (e.g., 'Brazilian immigrants come from less able races and this explains why they are not as well off as most Portuguese people' and 'Compared with the Portuguese people, Brazilian immigrants are very different in the language that they speak'). The participants indicated the extent to which they agreed with each statement on a 7-point scale varying from 1 (totally disagree) to 7 (totally agree). The scores were submitted to an exploratory factor analysis (using the principal axis factoring method of extraction), which revealed only one factor that explained $34.52 \%$ of the variance (eigenvalue $=2.07$; factor loadings from .38 to .69 ; $\alpha=.72)$. We compared the mean prejudice scores between the two experimental conditions. A $t$-test for independent samples showed that there was no significant difference between participants who heard the Brazilian accent $(M=2.20 ; S D=0.80)$ and those who heard the Portuguese accent $(M=2.18 ; S D=0.99), t(67)=0.09$, $p=.928$.

Manipulation Check. At the end of the procedure, we asked the participants to indicate the candidate's accent. Only one participant answered this question incorrectly. As a result, he was excluded from the analysis and the final sample was therefore 71 students.

\section{Results}

We regressed discrimination on the accent (Portuguese vs. Brazilian), prejudice, and the interaction term. The results showed a reliable main effect of accent, $b=.37$, $t(67)=2.21, p=.031, \eta_{p}^{2}=.26$. Importantly, this effect was qualified by a reliable interaction between prejudice and accent, $b=.51, t(67)=2.67, p=.010, \eta_{\mathrm{p}}^{2}=.31$. This means that prejudice moderates the influence of 
accent on discrimination. As can be seen in Figure la, low-prejudice participants $(-1.0 S D$ below the prejudice mean) were equally likely to hire the Portuguese $(M=2.97, S D=0.16)$ and the Brazilian $(M=3.06$, $S D=0.18)$ candidate, $t(67)=0.37, p=.714$. However, when prejudice was high $(+1 S D$ above the prejudice mean), the probability of hiring the Portuguese candidate $(M=3.25, S D=0.16)$ was greater than the probability of hiring the Brazilian candidate $(M=2.43$, $S D=0.18), t(67)=3.46, p=.001$. This means that listening to the target's accent had an influence on discrimination only in participants who were more prejudiced against Brazilian immigrants.

\section{Discussion}

This study provides the first experimental evidence that listening to a target's accent (native vs. immigrant) influences discrimination against this target, with this influence being moderated by prejudice. This result supports our first hypothesis, according to which only prejudiced individuals should be more likely to use information about targets' accents when making a decision about hiring candidates for a job, even when these candidates have the same professional experience. This means that accent leads to discrimination only in individuals who already have negative attitudes about a target's membership group. According to our rationale, this occurs because individuals engage in a legitimizing process in which the perception of the quality of an accent plays a central role. The next study addresses this hypothesis.

\section{Study 2}

This study intended to replicate Study 1 and go further by analysing how information about accents leads to discrimination in highly prejudiced individuals. As in the previous study, the participants were invited to take part in an online study conducted using a decisionmaking scenario used in recruiting candidates for a job. Once again, we manipulated the candidates' accents, which were either European or Brazilian Portuguese. The participants then answered a measure-of-accent assessment and indicated the probability of their hiring the candidate (discrimination measure). We predicted that hearing a target accent (native vs. immigrant) influences discrimination against this target only in highly prejudiced individuals. Considering that the perception of accent quality is a legitimizing factor of discrimination, then this perception should work as a mediator of the accent influence in the discrimination, process similar to that seen in previous studies (e.g., Lima-Nunes et al., 2013, Study 1). According to our rationale, and based on the results of the pilot study showing that discrimination based on accent is perceived as legitimate, the influence of accent on the hiring decision should be mediated by an assessment of the candidate's accent, because accents trigger a process of legitimation that is needed to justify the decision to hire a member of the ingroup.

\section{Method}

Participants and Design. One hundred and twenty-nine Portuguese university students participated in this study. However, five participants missed
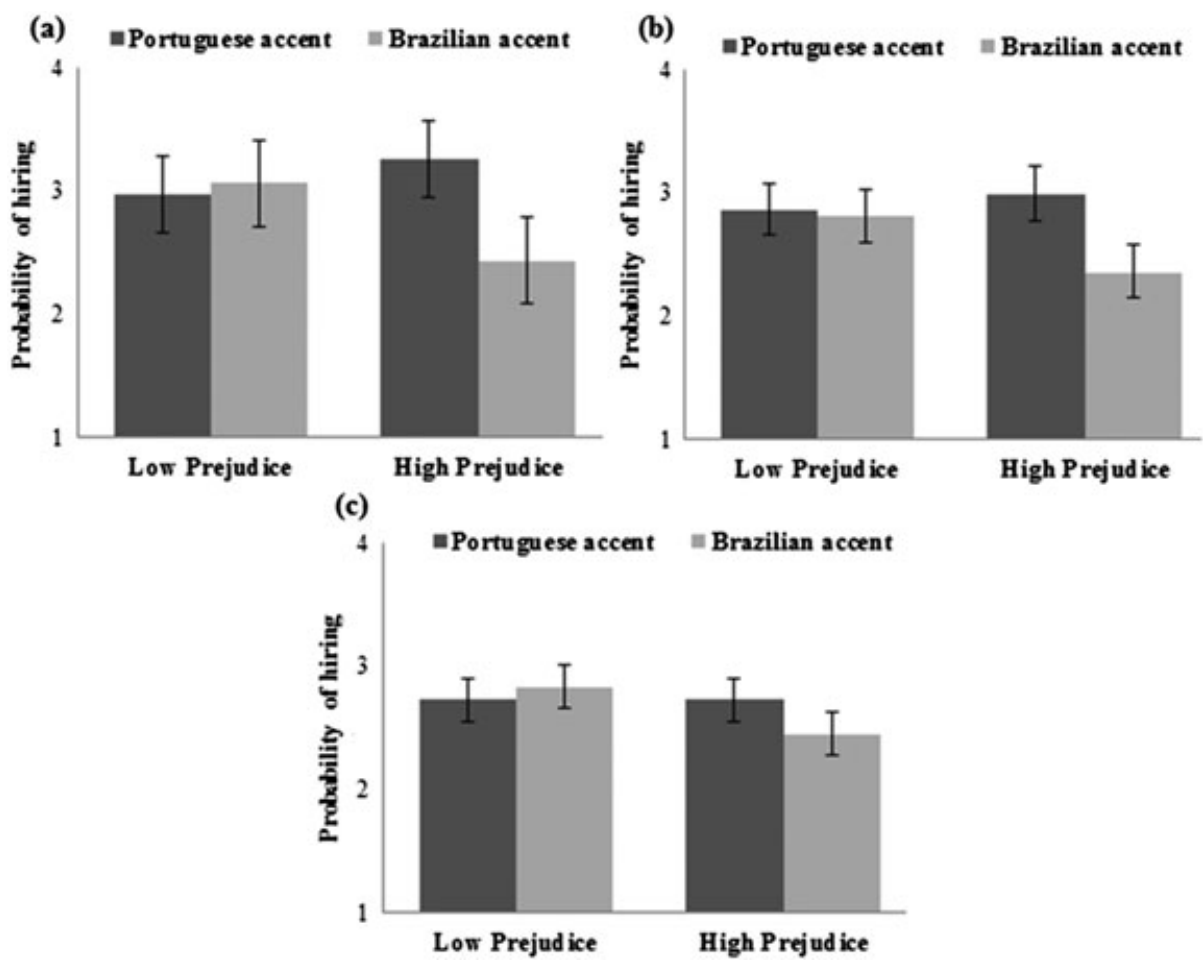

Fig. 1: Probability of hiring the Portuguese and Brazilian candidates as a function of candidates' accent and prejudice in Study 1 (a), Study 2 (b) and Study 3 (c) 
the manipulation check, so the final sample was 124 students $\left(M_{\mathrm{age}}=23.7, S D=4.83 ; 60\right.$ male and $64 \mathrm{fe}$ male). The participants were randomly allocated to one of two conditions (Portuguese accent vs. Brazilian accent) of a between-subject single-factor design.

Accent Manipulation. The content of the manipulation was the same as that used in Study 1 . Thus, the participants were exposed to and evaluated one of the two candidates, this presentation being fully randomized.

Assessment of Accent Measure. We developed a 12-item measure to assess the candidate's accent (e.g., 'understandable', 'sounds good', 'correct', 'ugly', and 'nice'). The participants indicated the extent to which each of the adjectives described the speech that they had just heard using a 7 -point scale $(1=$ not at all; $7=a$ lot). The scores were submitted to exploratory factor analysis (using the principal axis factoring method of extraction), which revealed only one factor that explained $32.39 \%$ of the variance (eigenvalue $=3.89$; factor loadings from .32 to .93). Three items were excluded because they had low factor loadings (under .30). Reliability analysis indicated that this scale had good internal consistency $(\alpha=.84)$.

Discrimination Measure. The measure was the same used in the previous study, in which participants indicated the probability of their hiring each candidate on a 4-point scale varying from 1 (not at all likely) to 4 ( very likely).

Manipulation Checks. We used the same manipulation check as in the previous study. Five participants did not answer this question correctly and were excluded from the analysis.

Prejudice Measure. The measure consisted of the same six items from the Portuguese version of the blatant and subtle prejudice against Brazilian immigrants scale used in a previous study $(\alpha=.72)$. We compared the mean scores of prejudice between the two conditions of the experiment. A $t$-test for independent samples showed that there was no significant difference between participants who heard the Brazilian accent $(M=2.26 ; S D=0.85)$ and those who heard the Portuguese accent $(M=2.22 ; S D=1.05), t(72)=0.16, p=.874$.

\section{Results}

We used a multiple-regression approach (Baron $\delta$ Kenny, 1986) to test whether the influence of accent on discrimination is moderated by prejudice and mediated by the assessment of the accent in question. For this purpose, we estimated three regression models. The parameters estimated for the three steps are shown in Table 1.
In the first model, we regressed discrimination on accent, prejudice, and the interaction term. The results showed a reliable main effect of accent. Importantly, the interaction between prejudice and accent predicted discrimination. This means that our first hypothesis that prejudice moderates the relationship between accent and discrimination was corroborated. As can be seen in Figure 1b, low-prejudice participants $(-1.0 S D$ below the prejudice mean) were equally likely to hire the Portuguese $(M=2.86, S D=0.11)$ and the Brazilian $(M=2.80, S D=0.11)$ candidate, $t(120)=0.37, p=.714$. However, in participants with high prejudice $(+1 S D$ above the prejudice mean), the Portuguese candidate $(M=2.98, S D=0.11)$ was more likely to be hired than the Brazilian one $(M=2.35, S D=0.10), t(120)=4.20$, $p<.001$. This means that the accent had an influence on discrimination only in participants who were more prejudiced against Brazilian immigrants.

In the second model, we regressed the assessment of accent on prejudice, accent, and the interaction term. The results indicated that accent has a reliable effect on the assessment of accent, demonstrating that the Portuguese accent $(M=4.80, S D=0.11)$ is more positively evaluated than the Brazilian accent $(M=4.39$, $S D=0.11), t(120)=2.63, p=.010$. Importantly, this effect is moderated by prejudice in such a way that lowprejudice participants $(-1.0 S D$ below the prejudice mean) showed no difference in the way they assessed the Portuguese accent $(M=4.67, S D=0.16)$ and the Brazilian accent $(M=4.60, S D=0.16), \quad t(120)=0.32$, $p=.745$. However, high-prejudice participants $(+1 S D$ above the prejudice mean) assessed the Portuguese accent more positively $(M=4.94, S D=0.16)$ than the Brazilian accent $(M=4.19, S D=0.15), t(120)=3.37$, $p=.001$. This means that only individuals with more negative attitudes against Brazilian immigrants perceive

Table 1. Parameters estimated according to regression models used in analysis of the role of assessment of accent in the influence of accent on discrimination

\begin{tabular}{|c|c|c|c|}
\hline \multirow[b]{3}{*}{ Predictors } & \multicolumn{3}{|c|}{ Criterion variables } \\
\hline & Step 1: D & Step 2: AA & Step 3: D \\
\hline & $b$ & $b$ & $b$ \\
\hline Intercept & $2.75^{* *}$ & $4.60 * *$ & $2.75^{\star *}$ \\
\hline Accent (A) & $0.35 * *$ & $0.41 * *$ & $0.19^{*}$ \\
\hline Prejudice (P) & -0.09 & -0.03 & -0.07 \\
\hline$A \times P$ & $0.31 * *$ & $0.36^{*}$ & 0.17 \\
\hline $\begin{array}{l}\text { Assessment o } \\
\text { accent (AA) }\end{array}$ & & & $0.38^{* *}$ \\
\hline$A A \times P$ & & & 0.00 \\
\hline \multirow[t]{3}{*}{$\begin{array}{l}\text { Model } \\
\text { information }\end{array}$} & $R=.39$ & $R=.30$ & $R=.65$ \\
\hline & $\begin{array}{l}R_{\text {Adjusted }}^{2}=.13 \\
F(3,120)=722\end{array}$ & $\begin{array}{l}R^{2} \text { Adjusted }=.07 \\
F(3,120)=4.01\end{array}$ & $\begin{array}{l}R_{\text {Adjusted }}^{2}=.40 \\
F(5118)=1710\end{array}$ \\
\hline & $p<.001$ & $p<.01$ & $p<.001$ \\
\hline
\end{tabular}

Note: $b=$ unstandardized coefficients; $\mathrm{D}$, discrimination.

${ }^{*} p<.05$.

$* * p<.01$ 
the quality of a Portuguese accent as better than a Brazilian one.

In the third model, we added the assessment of accent and its interaction with prejudice to predict discrimination. The results indicated that the effect of the assessment of accent on discrimination was significant. The interaction effect between accent and prejudice declined substantially and was no longer significant. This result indicates that the relationship between accent and discrimination, besides being moderated by prejudice, is mediated by the assessment of the target's accent. The mediation effect was reliable with 5000 bias corrected resamples from bootstrapping (indirect effect $=0.16$; 95\% CI: 0.04 to 0.31 ). To estimate the confidence intervals through bootstrapping, we used structural equation modelling with AMOS for Windows. In the Hayes PROCESS, this procedure is equivalent to model 59 (Hayes, 2013).

In order to interpret this mediated-moderation, we analysed the effect of accent on discrimination against the Brazilian candidate by taking into account different levels of prejudice. Specifically, we broke down the mediating effect of assessment of accent into participants with a low prejudice (i.e., those with $-1.0 S D$ below the prejudice mean) and those with a high prejudice (i.e., those with $+1.0 S D$ above the prejudice mean). As Figure 2a shows, for participants with higher levels of prejudice, the effect of accent on discrimination was mediated by the assessment of the accent (indirect effect $=0.29 ; 95 \% \mathrm{CI}$ : 0.08 to 0.54 with 5000 bias corrected resamples through bootstrapping). In other words, for highly prejudiced individuals, the accent of a candidate speaking European Portuguese is better evaluated than that of a candidate speaking Brazilian Portuguese, which in turn leads to the Portuguese candidate being hired instead of the Brazilian candidate. For participants with lower levels of prejudice, accent predicted neither discrimination nor the assessment of accent (indirect effect $=-0.10 ; 95 \% \mathrm{CI}$ : -0.29 to 0.05 ).

\section{Discussion}

This study reinforces evidence that the target accent triggers discrimination against this target, which supports our first hypothesis. In fact, the results replicate the previous study, showing that a candidate with a Portuguese accent is significantly more likely to be hired than one having a Brazilian accent, by more prejudiced participants but not by less prejudiced ones.

Importantly, confirming our second hypothesis, the results showed that the influence of accent on discrimination is mediated by individual perception of the quality of the accent concerned. This means that the assessment of an accent's quality can be the psychological mechanism that underlies the influence of accent on discrimination. In other words, in assessing a speaker's accent, prejudiced individuals tend to evaluate the ingroup accent more positively in a manner that legitimates their decision, which was made in a context of intergroup discrimination.

Despite providing evidence for our hypotheses, the findings would be stronger if we had given the participants the opportunity to hear both candidates and then decide which one to hire. Moreover, stronger evidence for the role played by accent quality would have been obtained if we had controlled for the effect of stereotyping, because the accent effect can be confounded with the way individuals use warmth and competence stereotypes when evaluating standard and non-standard accent speakers (e.g., Yzerbyt et al., 2005). To overcome these limitations, we carried out a third study with a within-subject design.

\section{Study 3}

This study intended to replicate the previous ones by using a within-subject design where accent leads to discrimination, with this influence being moderated by prejudice and mediated by assessment of the candidate's

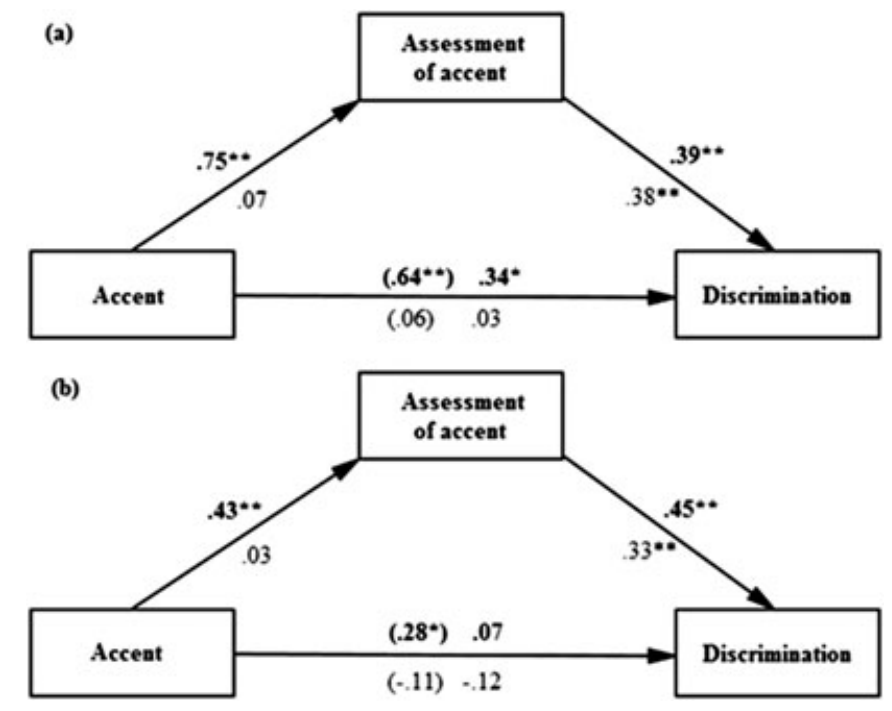

Fig. 2: The effect of accent on discrimination moderated by prejudice (coefficients in bold refer to participants with higher levels of prejudice) and mediated by assessment of accent in Study 2 (a) and Study 3 (b) 
accent. Moreover, we measured warmth and competence stereotypes to test the mediating role of accent quality even after controlling for the effect of stereotyping. As in the previous study, the participants were invited to take part in an online study conducted using a decision-making scenario used in recruiting candidates for a job. They first heard one of two recorded excerpts of a job interview. Next, they answered questions designed to assess the accent, attributed scores to the candidate's warmth and competence, and indicated the probability of their hiring the candidate (discrimination measure). Then, the participants heard the other recording and answered the questions again for the other candidate. At the end, the participants answered the prejudice questionnaire. We hypothesized that accent influences discrimination in highly prejudiced participants. Importantly, if the influence of accent is because of participants' perception of the features of the target's accent, this influence should be mediated by the perception of the accent's quality. Instead, if the influence of accent is motivated by stereotyping, this influence should be mediated by the greater attribution of warmth stereotypes to the Brazilian than to the Portuguese target and lesser attribution of competence stereotypes to the Brazilian than to the Portuguese target, because Brazilians are perceived having low status and forming an uncompetitive outgroup (Lima-Nunes, 2013).

\section{Method}

Participants and Design. One hundred and five Portuguese university students participated in this study $\left(M_{\text {age }}=24.1, S D=4.37 ; 58\right.$ male and 47 female $)$. This experiment consisted of a single factor (Portuguese accent vs. Brazilian accent) within-subject design.

Accent Manipulation. The content of the manipulation was the same as that used in Studies 1 and 2 . However, because we used a within-subject design, the participants were exposed to and evaluated one candidate and then were exposed to and evaluated the other candidate, this presentation being fully randomized.

Assessment of Accent Measure. The measure was the assessment of the candidates' accents that was used in a previous study ( $\alpha=.85$ for Portuguese accent and $\alpha=.89$ for Brazilian accent).

Stereotype Measure. We used the competence and warmth stereotypes (Fiske et al., 2002) to measure Brazilian and Portuguese stereotypes. We asked the participants to indicate the extent to which the candidates presented each of seven traits, using a 7-point scale $(1=$ not at all; $7=a$ lot $)$. We submitted the scores to two exploratory factor analyses (using the principal axis factoring method of extraction) with varimax rotation. For the Portuguese stereotypes, the results revealed two factors that explained $49.98 \%$ of the variance (eigenvalues $=2.09$ and 1.90) for competence stereotype factor loadings from .58 (competitive) to .68 (independent), $\alpha=.73$ and warmth stereotypes from .55 (trustworthy) to .80 (warm), $\alpha=.77$. For the Brazilian stereotypes, the results also revealed two factors that explained $50.70 \%$ of the variance (eigenvalues $=2.52$ and 1.53) for competence stereotype factor loadings from .34 (competent) to .72 (competitive), $\alpha=.76$ and warmth stereotypes from .45 (warm) to .82 (trustworthy), $\alpha=.78$.

Discrimination Measure. We used the same measure employed in the previous studies; that is, the participants indicated the probability of their hiring each candidate on a 4-point scale varying from 1 (not at all likely) to 4 (very likely).

Prejudice Measure. The measure consisted of the same six items from the Portuguese version of the blatant and subtle prejudice scale used in the previous studies $(\alpha=.79)$.

\section{Results}

We expected that the influence of accent on the probability of the candidates being hired would be moderated by prejudice. That is, the Portuguese candidate would be more likely to be hired than the Brazilian candidate, but only by more prejudiced participants. Moreover, we predicted that this moderation would be mediated by the assessment of the candidate's accent, even when taking into account the role played by the warmth and competence stereotypes attributed to the targets. To test these hypotheses, we estimated a mediated-moderation model in a within-subject design. In line with the suggestions of Judd, Kenny and McClelland (2001), we used difference scores to represent the within subjecteffect of the target on discrimination (i.e., the dependent variable), the assessment of the candidate's accent, and the warmth and competence stereotypes (i.e., the mediators) in multiple regression analyses. In this sense, we estimated four regression models. The parameters estimated for the three steps are shown in Table 2.

In the first model, we regressed the difference scores for discrimination $(D)$ on prejudice. In this model, the intercept represents the main effect of the targets' accents on discrimination, while the prejudice effect represents the two-way interaction between accent and prejudice. As predicted, the results showed that the accent per se was not sufficient for discrimination to take place. However, the effect of prejudice was reliable and indicated that prejudice moderates the influence of accent on discrimination. As can be seen in Figure lc, low-prejudice participants $(-1 S D$ from prejudice mean) were just as likely to hire the Portuguese candidate $(M=2.72, S D=0.09)$ as the Brazilian one 


\begin{tabular}{|c|c|c|c|c|c|}
\hline \multirow[b]{4}{*}{ Predictors } & \multicolumn{5}{|c|}{ Criterion variables } \\
\hline & \multirow[t]{2}{*}{ Step 1: D } & \multicolumn{3}{|c|}{ Step 2: } & \multirow[t]{2}{*}{ Step 3: D } \\
\hline & & AA & CS & WS & \\
\hline & $b$ & $b$ & $b$ & $b$ & $b$ \\
\hline Accent (I) & 0.08 & $0.23 *$ & 0.10 & $-0.25^{\star}$ & -0.02 \\
\hline Prejudice (P) & $0.18^{*}$ & $0.18^{+}$ & -0.01 & 0.13 & 0.09 \\
\hline $\mathrm{AA}$ & & & & & $0.39 * *$ \\
\hline CS & & & & & 0.14 \\
\hline WS & & & & & 0.04 \\
\hline$P * A A$ & & & & & 0.06 \\
\hline$P * C S$ & & & & & -0.02 \\
\hline$P * W S$ & & & & & -0.04 \\
\hline \multirow[t]{4}{*}{ Model Information } & $R=.26$ & $R=.27$ & $R=.12$ & $R=.28$ & $R=.65$ \\
\hline & $R_{\text {Adjusted }}^{2}=.05$ & $R_{\text {Adjusted }}^{2}=.06$ & $R_{\text {Adjusted }}^{2}=-.005$ & $R_{\text {Adjusted }}^{2}=.06$ & $R_{\text {Adjusted }}^{2}=.38$ \\
\hline & $F(2,102)=3.60$ & $F(2,103)=4.10$ & $F(2,101)=0.74$ & $F(2,101)=4.39$ & $F(8,95)=8.80$ \\
\hline & $p=.031$ & $p=.019$ & $p=.478$ & $p=.015$ & $p<.001$ \\
\hline
\end{tabular}

Note: $b$ = unstandardized coefficients; D, discrimination; I, intercept; AA, assessment of accent; CS, competence stereotype; WS, warmth stereotype. ${ }^{*} p<.05$.

${ }^{* *} p<.01$.

${ }^{+} p=.065$.

$(M=2.83, S D=0.09), t(102)=-0.98, p=.331$. However, when prejudice was high (+l $S D$ from prejudice mean), the probability of hiring the Portuguese candidate $(M=2.72, S D=0.09)$ was greater than the probability of hiring the Brazilian candidate $(M=2.44, S D=0.09)$, $t(102)=2.50 p=.014$. As in Studies 1 and 2, this means that the targets' accents influenced discrimination only in participants who were more prejudiced against Brazilian immigrants.

In the second model, we regressed the difference scores of the mediators (AA, CS, and WS) on prejudice. In this model, the intercept represents the mean difference between the experimental conditions used in assessing accent and competence and warmth stereotypes. The results indicated that accent has a reliable effect only in assessing accent and warmth stereotypes. That is, the Portuguese candidate was judged to have a better accent $(M=4.59, S D=0.83)$ than the Brazilian candidate $(M=4.36, S D=0.97)$, but the Brazilian immigrant was evaluated as being warmer $(M=4.37$, $S D=0.77)$ than the Portuguese candidate $(M=4.12$, $S D=0.77$ ).

In the last model, we regressed discrimination on prejudice, on the difference scores of the mediators, and on the interaction terms. The results indicated that only the assessment of accent predicted discrimination as this was the only mediating variable in the process according to 5000 bias corrected resamples obtained by bootstrapping (indirect effect $=0.04 ; 95 \% \mathrm{CI}$ : 0.01 to $0.10)$, even when controlling for warmth and competence. To estimate the confidence intervals through bootstrapping, we used structural equation modelling with AMOS for Windows. There is no equivalent model for this mediated moderation in the within-subject design in the Hayes PROCESS (Hayes, 2013). Moreover, the effect of prejudice decreased substantially and was no longer significant, which indicates that assessment of accent mediates the role played by prejudice in the relation between accent and discrimination.

In order to interpret this mediated moderation, as in the previous study, we analysed the effect of accent on discrimination against immigrants by taking into account different levels of prejudice. Specifically, we broke down the mediating effect of assessment of accent into low-prejudice participants (i.e., those with - 1.0 SD below the prejudice mean) and high-prejudice participants (i.e., those with $+1.0 S D$ above the prejudice mean). As Figure $2 \mathrm{~b}$ shows, for participants with higher levels of prejudice, the effect of accent on discrimination was mediated by the assessment of accent (indirect effect $=0.08 ; 95 \%$ CI: 0.01 to 0.25 ). In other words, being highly prejudiced significantly predicted a better evaluation of the Portuguese accent than the Brazilian accent, which in turn led to the Portuguese candidate to be hired more than the Brazilian one. For participants with lower levels of prejudice, the candidate's accent predicted neither discrimination nor the assessment of accent (indirect effect $=0.00 ; 95 \% \mathrm{CI}$ : -0.07 to 0.06 ).

\section{Discussion}

The main effect of accent we found in the two previous studies did not arise in this one. We think this is because of the within-subject experimental design used here. Indeed, participants had the opportunity to compare the two candidates for the job, and thus, it is very likely that the comparison aroused anti-prejudiced concerns that motivated the reduction in accent strength. However, the pattern is a strong test for our prediction according to which the influence of accent on discrimination is moderated by prejudice and mediated by assessment of accent. Using a different design, results demonstrated that targets' accents influenced discrimination only when prejudice was high and this influence was 
mediated by the assessment of the target's accent. The effect occurred independently of stereotyping about the target. Although accent predicted warmth stereotypes, in the sense that the participants attributed more warmth stereotypes to the Brazilian candidate than to the Portuguese one, which corroborates other research (Edwards, 1982; Fuertes et al., 2012), these stereotypes did not mediate the influence of accent on discrimination against immigrants.

\section{General Discussion}

We analysed the influence of accent on discrimination against immigrants. Study l explored the role of prejudice in this influence and revealed that listening to an immigrant's accent led to discrimination against this immigrant only in the case of the more prejudiced participants. The question that arises here is whether the mere fact of an accent being perceived as native versus nonnative is sufficient to lead to discrimination against the non-native speaker. Indeed, in people with low levels of prejudice, accent does not lead to discrimination against the immigrant. Importantly, this pattern of results was replicated in Studies 2 and 3.

The mediating role played by the assessment of accent, as demonstrated in Study 2 and replicated in Study 3, follows and extends the results of previous studies, demonstrating the importance of legitimizing factors to understand discrimination (Pereira, Vala, \& Leyens, 2009; Pereira, Vala, \& Costa-Lopes, 2010). One of the innovative aspects of this research programme is demonstrating that the evaluation that people make about the accent of a target group assumes this role in legitimizing prejudiced individuals. In accordance with our predictions, for more prejudiced individuals, information about accent is an important criterion when they make hiring decisions for job candidates; insofar, this decision is mediated by assessment of the quality of the target's accent. Our rationale is that the assessment of a speaker's accent is perceived as a non-prejudiced way of justifying discriminatory behaviour, as we found in the pilot study. While it is morally and ethically unacceptable to use information about race or ethnicity to discriminate (Lippi-Green, 1997), evaluating the way that a person speaks is commonly accepted and perceived as legitimate in society (Gluszek \& Dovidio, 2010; Ng, 2007).

\section{Theoretical Implications}

In current day globalized societies where immigrants are competing with nationals for jobs, the study of hiring discrimination has high social relevance. Indeed, accent is one of the key markers differentiating immigrants from the national majority. Studying the accent effect has practical implications for social psychologists not only because it provides insights about the dynamics of intergroup relations involving linguistic skills but also because it is useful for planning intervention in several social situations, especially in the labourmarket context. The current research programme goes beyond the implications of the applied effect of speakers' accent, because it also contributes to theorizing and research on intergroup discrimination in at least three ways: (i) it sheds light on literature about the accent effect because it shows experimental evidence for the influence of accent on actual discrimination against immigrants; (ii) it suggests that accent per se is not enough to trigger discrimination because the accent effect would depend on negative attitudes that individuals have about the target groups; and (iii) it highlights the legitimizing role played by accent in social inequality.

In fact, this paper contributes to a better understanding of the role played by categorization in intergroup discrimination (Park \& Judd, 2005) because it shows experimentally that the accessibility of social categories per se is not sufficient to lead to discrimination and that this pervasive effect occurs only in individuals who have negative attitudes toward the target group. We show that accents are really linked to categorization and that this categorization then triggers negative evaluations about targets (Fuertes et al., 2012; Rakić et al., 2011) and leads to discrimination against them, specifically immigrants with different accents. Our research goes further and shows in Study 3 that the psychological mechanism that explains the influence of accent on discrimination is, in fact, the assessment of the quality of the target's accent even after controlling for the effect of stereotyping.

We also believe that this paper contributes to the study of processes by which social inequalities are legitimated (Costa-Lopes et al., 2013), as it reveals a new, seemingly unprejudiced argument that is capable of legitimizing discrimination (Pereira et al., 2010). Indeed, perceiving the quality of an accent to be legitimate information in deciding in favour of a native candidate is in line with social psychology research and theory, which reveals that prejudice and discrimination persist because individuals have developed indirect ways and legitimated forms of discrimination (e.g., Crandall \& Eshleman, 2003; Dovidio \& Gaertner, 2004; Sidanius \& Pratto, 1999). Moreover, as pointed out by Pereira et al. (2009), the relationship between prejudice and discrimination needs to be legitimized because individuals' self-concepts hold internalized egalitarian justice principles that require them to have good reasons to discriminate. This paper shows that the assessment of the way a person speaks can work as a strong argument to justify discrimination.

\section{Limitations and Further Directions}

Although the results reported here support our hypotheses, these studies have some important limitations. Although contributing to the field of accent research by experimentally demonstrating the prejudiced-based accent effect on actual discrimination, we did not manipulate prejudice. The observational nature of the role played by prejudice on accent effect weakens the evidence in support the idea that discrimination against non-standard speakers is motivated by prejudice. We think that further research can improve the evidence 
for this hypothesis by manipulating not only the accent but also prejudice. In addition, our predictions clearly posit that accent influences only individuals who already have prejudiced attitudes against targets' social category, but does not provide insight about the accent effect on individuals' prejudiced attitudes. Future research can better investigate this issue by testing the role played by accent on factors known to directly influence prejudice, such as intergroup contact and the quality of this contact.

Despite these limitations, the research presented here shows strong evidence that accent influences discrimination only in more prejudiced people. Furthermore, this effect is mediated by assessment of the target's accent in the sense that the participants tend to evaluate the ingroup accent more positively as a way of justifying their discriminatory behaviour as legitimate.

\section{Acknowledgements}

This work was partially supported by a grant from CNPq, Ministério da Ciência e Tecnologia, Brazil, awarded to Luana Souza (SWE-245390/2012-0), by a grant from the Institute of Social Sciences of the University of Lisbon (PEst-OE/SADG/LA0013/2013), and by a grant from the Fundação para a Ciência e a Tecnologia, awarded to Cicero Roberto Pereira (PTDC/PSI-PSO/114159/2009). We thank the Lisbon SPARC Research Group of the Institute of Social Sciences of the University of Lisbon for their helpful comments on previous versions of these studies. We would also like to thank Eva G. T. Green and two reviewers for their insightful comments that greatly contributed to improving this paper.

\section{References}

Allport, G. W. (1954). The nature of prejudice. Wokingham: Addison-Wesley.

Baron, R. M., \& Kenny, D. A. (1986). The moderatormediator variable distinction in social psychological research: Conceptual, strategic, and statistical considerations. Journal of Personality and Social Psychology, 51, 1173-1182. http://dx.doi.org/10.1037/0022-3514.51.6.1173.

Boyd, S. (2003). Foreign-born teachers in the multilingual classroom in Sweden: The role of attitudes to foreign accent. International Journal of Bilingual Education and Bilingualism, 6, 283-295. http://dx.doi.org/10.1080/ 13670050308667786.

Bradac, J. J. (1990). Language attitudes and impression formation. In H. Giles \& W. P. Robinson (Eds.), Handbook of language and social psychology (pp. 387-412). New York: Wiley.

Bresnahan, M. J., Ohashi, R., Nebashi, R., Liu, W. Y., \& Shearman, S. M. (2002). Attitudinal and affective response toward accented English. Language and Communication, 22, 171-185. http://dx.doi.org/10.1016/ S0271-5309(01)00025-8.

Costa-Lopes, R., Dovidio, J. F., Pereira, C. R., \& Jost, J. T. (2013). Social psychological perspectives on the legitimation of social inequality: Past, present and future. European
Journal of Social Psychology, 43, 229-237. http://dx.doi.org/ 10.1002/ejsp.1966.

Costa-Lopes, R., Pereira, C. R., \& Judd, C. M. (2014). Categorisation salience and ingroup bias: The buffering role of a multicultural ideology. International Journal of Psychology, 49 508-512. http://dx.doi.org/10.1002/ ijop.12044.

Crandall, C. S., \& Eshleman, A. (2003). A justificationsuppression model of the expression and experience of prejudice. Psychological Bulletin, 129, 414-446. http://dx. doi.org/10.1037/0033-2909.129.3.414.

Derwing, T. M., \& Munro, M. J. (2009). Putting accent in its place: Rethinking obstacles to communication. Language Teaching, 42, 476-490. http://dx.doi.org/10.1017/ S026144480800551X.

Devine, P. G. (1989). Stereotypes and prejudice: Their automatic and controlled components. Journal of Personality and Social Psychology, 56, 5-18. http://dx.doi.org/10.1037/ 0022-3514.56.1.5.

Dovidio, J. F. (2001). On the nature of contemporary prejudice: The third wave. Journal of Social Issues, 57, 829-849. http://dx.doi.org/10.1111/0022-4537.00244.

Dovidio, J. F., \& Gaertner, S. L. (2000). Aversive racism and selection decisions: 1989 and 1999. Psychological Science, 11, 315-319. http://dx.doi.org/10.1111/1467-9280.00262.

Dovidio, J. F., \& Gaertner, S. L. (2004). Aversive racism. In M. P. Zanna (Ed.), Advances in experimental social psychology (Vol. 36, pp. 1-52). Thousand Oaks, CA: Sage.

Edwards, J. (1982). Language attitudes and their implications among English speakers. In E. B. Ryan, \& H. Giles (Eds.), Attitudes toward language variation: Social and applied contexts (pp. 20-33). London: Edward Arnold.

Edwards, J. (1999). Refining our understanding of language attitudes. Journal of Language and Social Psychology, 18, 101-110. http://dx.doi.org/10.1177/0261927X99018001007.

European Commission. (2008). Discrimination in the European Union: Perceptions, experiences and attitudes (Special Eurobarometer 296, Wave 69.1). Retrieved January 07, 2013, from http://ec.europa.eu/public_opinion/archives/ ebs/ebs_296_en.pdf

Fiske, S. T., Cuddy, A. J. C., Glick, P., \& Xu, J. (2002). A model of (often mixed) stereotype content: Competence and warmth respectively follow from perceived status and competition. Journal of Personality and Social Psychology, 82, 878-902. http://dx.doi.org/10.1037/00223514.82.6.878.

Fuertes, J. N., Gottdiener, W., Martin, H., Gilbert, T. C., \& Giles, H. (2012). A meta-analysis of the effects of speakers' accents on interpersonal evaluations. European Journal of Social Psychology, 42, 120-133. http://dx.doi.org/10.1002/ ejsp.862.

Gaertner, S. L., \& Dovidio, J. F. (2005). Understanding and addressing contemporary racism: From aversive racism to the common ingroup identity model. Journal of Social Issues, 61, 615-639. http://dx.doi.org/10.1111/j.15404560.2005.00424.x.

Giles, H., \& Johnson, P. (1987). Ethnolinguistic identity theory: A social psychological approach to language maintenance. International Journal of the Sociology of Language, 68, 69-99. http://dx.doi.org/10.1515/ijsl.1987.68.69.

Gluszek, A., \& Dovidio, J. F. (2010). The Way They Speak: A social psychological perspective on the stigma of non- 
native accents in communication. Personality and Social Psychology Review, 14, 214-237. http://dx.doi.org/10.1177/ 1088868309359288.

Grondelaers, S., van Hout, R., \& Steegs, M. (2010). Evaluating regional accent variation in standard Dutch. Journal of Language and Social Psychology, 29, 101-116. http://dx.doi. org/10.1177/0261927X09351681.

Hayes, A. F. (2013). Introduction to mediation, moderation, and conditional process analysis: A regression-based approach. New York: Guilford Publications.

Hosoda, M., \& Stone-Romero, E. (2010). The effects of foreign accents on employment-related decisions. Journal of Managerial Psychology, 25, 113-132. http://dx.doi.org/ 10.1108/02683941011019339.

Hosoda, M., Stone-Romero, E. F., \& Walter, J. N. (2007). Listeners' cognitive and affective reactions to English speakers with standard American English and Asian accents. Perceptual and Motor Skills, 104, 307-326. http://dx.doi.org/ 10.2466/pms.104.1.307-326.

Huang, L., Frideger, M., \& Pearce, J. L. (2013). Political skill: Explaining the effects of nonnative accent on managerial hiring and entrepreneurial investment decisions. Journal of Applied Psychology, 98, 1005-1017. http://dx.doi.org/ $10.1037 / \mathrm{a} 0034125$.

Judd, C. M., Kenny, D. A., \& McClelland, G. H. (2001). Estimating and testing mediation and moderation in withinsubject designs. Psychological Methods, 6, 115-134. http:// dx.doi.org/10.1037/1082-989X.6.2.115.

Kinzler, K. D., Dupoux, E., \& Spelke, E. S. (2007). The native language of social cognition. Proceedings of the National Academy of Science, 104, 12,577-12,580. http://dx.doi.org/ 10.1073/pnas.0705345104.

Ko, S. J., Judd, C. M., \& Blair, I. V. (2006). What the voice reveals: Within- and between-category stereotyping on the basis of voice. Personality and Social Psychology Bulletin, 32, 806-819. http://dx.doi.org/10.1177/0146167206286627.

Lee, T. L., \& Fiske, S. T. (2006). Not an outgroup, not yet an ingroup: Immigrants in the Stereotype Content Model. International Journal of Intercultural Relations, 30, 751-768. http://dx.doi.org/10.1016/j.ijintrel.2006.06.005.

Lev-Ari, S., \& Keysar, B. (2010). Why don't we believe nonnative speakers? The influence of accent on credibility. Journal of Experimental Social Psychology, 46, 1093-1096. http://dx.doi.org/10.1016/j.jesp.2010.05.025.

Lima-Nunes, A., Pereira, C. R., \& Correia, I. (2013). Restricting the scope of justice to justify discrimination: The role played by justice perceptions in discrimination against immigrants. European Journal of Social Psychology, 43, 627-636. http://dx.doi.org/10.1002/ejsp.1981.

Lima-Nunes, A. V. (2013). Justice seems not to be for all: the role played by justice perceptions in discrimination against immigrants. (Doctoral dissertation). ISCTE-IUL, Lisbon, Portugal. Retrieved from http://hdl.handle.net/10071/ 6925

Lindemann, S. (2003). Koreans, Chinese or Indians? Attitudes and ideologies about nonnative English speakers in the United States. Journal of Sociolinguistics, 7, 348-364. http://dx.doi.org/10.1111/1467-9481.00228.

Lindemann, S. (2005). Who speaks "broken English"? US undergraduates' perception of nonnative English.
International Journal of Applied Linguistics, 15, 187-212. http://dx.doi.org/10.1111/j.1473-4192.2005.00087.x.

Lippi-Green, R. (1997). English with an accent. London: Routledge.

Moyer, A. (2004). Age, accents, and experience in second language acquisition: An integrated approach to critical period inquiry. Clevedon, UK: Multilingual Matters.

Ng, S. H. (2007). Language-based discrimination: Blatant and subtle forms. Journal of Language and Social Psychology, 26, 106-122. http://dx.doi.org/10.1177/ $0261927 X 07300074$.

Operario, D., \& Fiske, S. T. (2001). Stereotypes: Content, structures, process, and context. In R. Brown \& S. Gaertner (Eds.), Blackwell handbook of social psychology: Intergroup process (pp. 22-44). Malden, MA: Blackwell Publishers Ltd.

Park, B., \& Judd, C. M. (2005). Rethinking the link between categorization and prejudice within the social cognition perspective. Personality and Social Psychology Review, 9, 108-130. http://dx.doi.org/10.1207/ s15327957pspr0902_2.

Pereira, C., Vala, J., \& Costa-Lopes, R. (2010). From prejudice to discrimination: The legitimizing role of perceived threat in discrimination against immigrants. European Journal of Social Psychology, 40, 1231-1250. http://dx.doi.org/ 10.1002/ejsp.718.

Pereira, C. R., Vala, J., \& Leyens, J. P. (2009). From infrahumanization to discrimination: The mediation of symbolic threat needs egalitarian norms. Journal of Experimental Social Psychology, 45, 336-344. http://dx.doi.org/10.1016/j. jesp.2008.10.010.

Pettigrew, T. F., \& Meertens, R. W. (1995). Subtle and blatant prejudice in Western Europe. European Journal of Social Psychology, 25, 57-75. http://dx.doi.org/10.1002/ ejsp. 2420250106.

Rakić, T., Steffens, M. C., \& Mummendey, A. (2011). Blinded by the accent! The minor role of looks in ethnic categorization. Journal of Personality and Social Psychology, 100, 16-29. http://dx.doi.org/10.1037/a0021522.

Ruscher, J. B. (2001). The social psychology of prejudiced communication. New York: Guilford Press.

Sidanius, J., \& Pratto, F. (1999). Social dominance. New York: Cambridge University Press.

Tajfel, H. (1984). Intergroup relations, social myths and social justice in social psychology. In H. Tajfel (Ed.), The social dimension (Vol. 2, pp. 695-715). Cambridge: Cambridge University Press.

Vala, J., Lopes, D., \& Lima, M. (2008). Black immigrants in Portugal: Luso-tropicalism and prejudice. Journal of Social Issues, 64, 287-302. http://dx.doi.org/10.1111/j.15404560.2008.00562.x.

Yzerbyt, V., Provost, V., \& Corneille, O. (2005). Not competent but warm... Really? Compensatory stereotypes in the French-speaking World. Group Process Intergroup Relations, 8, 291-308. http://dx.doi.org/10.1177/1368430205053944.

Yzerbyt, V. Y., Rocher, S. J., \& Schadron, G. (1997). Stereotypes as explanations: A subjective essentialistic view of group perception. In R. Spears, P. J. Oakes, N. Ellemers, \& S. A. Haslam (Eds.), The social psychology of stereotyping and group life, (Vol. 8, pp. 20-50). Malden: Blackwell Publishing. 